\title{
The results of cutting disks testing for rock destruction
}

\author{
Aleksey Khoreshok ${ }^{1}$, Leonid Kantovich ${ }^{2}$, Vladimir Kuznetsov ${ }^{1}$, Elena Preis ${ }^{1}$, Dilshad \\ Kuziev $^{2}$ \\ ${ }^{1}$ T.F. Gorbachev Kuzbass State Technical University, 650000, Kemerovo, 28 Vesennya st., Russian \\ Federation \\ ${ }^{2}$ National Research Technical University "NITU “MISiS”, 119991, Moscow, 4 Leninsky av., Russian \\ Federation
}

\begin{abstract}
To determine the rational order of disk tools placement on the working body is necessary to know the maximum amount of rock, destroyed by the disk tool in benching cutting mode depending on the tool geometry parameters, physical and mechanical parameters of rocks. The article contains the definition of rational parameters of cutting disk tools as well as power and energy parameters of the destruction process by cutting disks and by executive body of the coal cutter. The rational geometric parameters of cutting discs are specified. It was found that each step of cutting with a minimum depth of penetration has its own maximum height of bench outcrop. The dependence of the volumes of large items destroyed by the disk tool on the cutting step height was determined. The existence of the cyclic alternation of destruction phases, regardless the fracture parameters, the height of the ledge outcrop, and tools like free cutting geometry were found. In contrast to the free cutting in benching mode of destruction two large fragments of rocks in one cycle were observed. Consequently, the cyclical nature of the destruction process in the benching mode will be characterized by two chips and crushing, and this cycling repeats throughout the destruction process with the same parameters of destruction.
\end{abstract}

\section{Introduction}

At present time studies of mining machinery and equipment increased greatly in coal basin areas of Russia. The reason of this is coal mining boosting in Kuzbass - the greatest Russian coal basin located in Western Siberia. Last decade coal mining in Kuzbass has increase by 6-10 million tons annually. The main part of Kuzbass coal is mined by open pit enterprises $-65 \%$. And now Kuzbass open pits are the leaders in new mining equipment implementation and research contractors [1]. Many studies have focused on the destructive influence of cutting tools on rock arrays [2-5]. Some studies were devoted to the analysis of different aspects of cutting process [6-14].

\footnotetext{
*Corresponding author: haa.omit@kuzstu.ru
} 
Another group of works is devoted to accuracy of measurements [15-18]. Destruction process modelling has become the topic of active research since the $2000^{\text {th }}$ [19-24]. Some studies are devoted to applying the results of research of cutting process in different kinds of equipment [25-29]. The significant part of research made by Kuzbass scholars (Western Siberia, Russia) belongs to improving characteristics of cutting instruments for rock destroying in coal mines and pits [30-37].

However production of highly effective cutting disks for rock destroying tools of mining machinery is still important for Kuzbass coal industry.

\section{Materials and methods}

The estimated scheme of the influence model of distributed single effort on a quarter of space with outgrowth is shown in Fig. 1, where the resultant of the force distribution on a horizontal surface is defined as:

$$
P=-\int_{0}^{0.1} \int_{-1}^{1}(z / l)\left(1-\cos \frac{2 \pi z}{l}\right) d z d x
$$

where $l$ - length of contact of the tool with the rock.

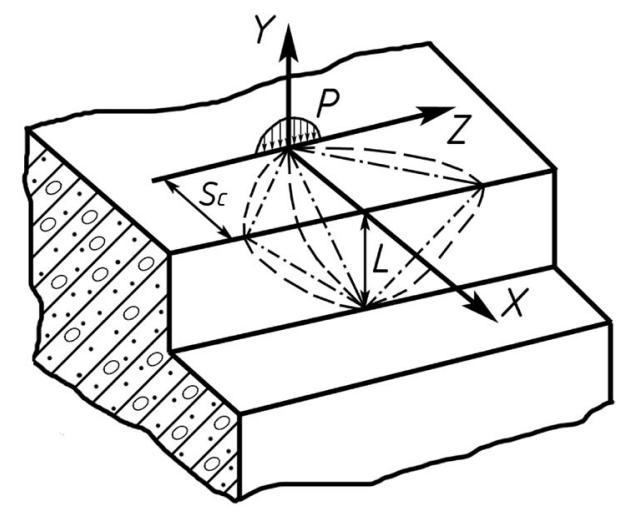

Fig. 1. The scheme of the disk tool and the rock interaction

Calculation of models was conducted at following input values:

$0.01 \leq S_{c} \leq 0.09 \mathrm{~m}, S_{c} \leq L \leq L^{\infty}$ with pitch $\Delta S_{c}=\Delta L=0.005 \mathrm{~m}$, where $L^{\infty}$ - unlimited length of the exposed surface.

The fracture surface is described by the criterion:

$$
F \leq \frac{\sqrt{2}}{2} \sqrt{\left(\sigma_{1}-\sigma_{2}\right)^{2}+\left(\sigma_{2}-\sigma_{3}\right)^{2}+\left(\sigma_{3}-\sigma_{1}\right)^{2}},
$$

where $\sigma_{1}, \sigma_{2}, \sigma_{3}$ - primary stresses.

The theoretical results describing the volume of the large destroyed element by disk tool are best described by the formula of the ellipsoid.

In Fig. 1 bar and dot-dash lines show the fracture surface, built on the formulae of ellipsoid and the pyramid respectively.

As a result, conducted research showed that the step of cutting $S_{c}$ - the distance from the line of action of the tool to the height of the projection influences on the distribution of the fracture surface plane $\mathrm{X} 0 \mathrm{Y}$. 
According to the results of modeling, a few dependences were built to define the maximum amount of material destroyed disk tool $V_{\max }$ for cutting step $S_{c}$ with unlimited height of projection's exposure $(L)$.

For ellipsoid:

$$
V_{e l}\left(S_{c}\right)=\left\{\begin{array}{l}
\frac{\pi}{3} S_{c}\left(-36+\frac{1080}{S_{c}+21}\right)\left(0.1 S_{c}^{2}-0.19 S_{c}+5.72\right), \text { where } 0.03 \leq S_{c} \leq 0.09 \mathrm{~m} ; \\
\frac{\pi}{3} S_{c}\left(\frac{1}{2} S_{c}^{2}+\frac{1}{2} S_{c}+3\right)\left(14.65-\frac{63.47}{S_{c}+4.33}\right), \text { where } 0 \leq S_{c} \leq 0.03 \mathrm{~m} .
\end{array}\right.
$$

For pyramid:

$$
V_{p y r}\left(S_{c}\right)=\frac{V_{e l}\left(S_{c}\right)}{\pi} .
$$

Results of calculation of the dependence of the volume of large elements $(V)$ destroyed by disk tool on the size of the cutting step $S_{c}$ are shown in Fig. 2.

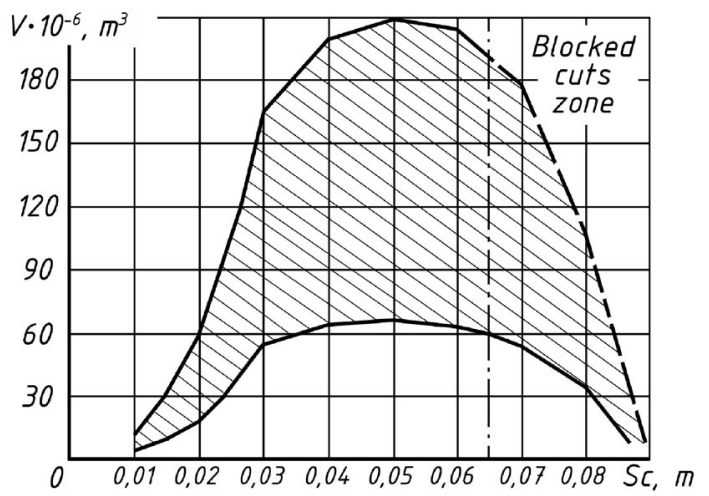

Fig. 2. Dependence of the volume of destroyed large element $V$ and cutting step $S_{c}$

It is likely that the surface of large elements of real materials having structural defects should be between the fracture surface of the ellipsoid and pyramids. Here, the amount of real materials is shown by the shaded area.

These curves reflect a dome-like character of the distribution. Volumes of maximum large elements separated from the array by disk tool are located in the area of $0.04 m \leq S_{c} \leq 0.06 m$ and $0.072 m \geq L_{\max } \geq 0.04 m$. The maximum amount of large elements is achieved at $S_{c}=0.05 \mathrm{~m}$ and $L_{\max }=0.055 \mathrm{~m}$. Therefore if $0.555 \leq S_{c} / L_{\max } \leq 1.5$ then maximum area of large elements $\left(V_{\max }\right)$ and maximum is achieved at the ratio of $S_{c} / L_{\max }=0.91$.

In order to confirm the results of simulations there were experimental studies conducted for destruction of sand-and-cement blocks with the following strength characteristics: compressive strength $\sigma_{\mathrm{c}}=28.0 \mathrm{MPa}$, ultimate tensile strength $\sigma_{\mathrm{t}}=4.0 \mathrm{MPa}$. The disk instruments had the following geometric parameters: diameter $D=0.16$ and $0.18 \mathrm{~m}$; wedge angle $\mathrm{F}=30$ and $35^{\circ}$. The geometrical dimensions of the projection and fracture parameters had the following values: cutting step $S_{c}=0.03,0.04$ and $0.05 \mathrm{~m}$; penetration depth $h=$ $0.005,0.01$ and $0.015 \mathrm{~m}$; height of exposure $L=0.03,0.04$ and $0.05 \mathrm{~m}$.

Experimental studies were carried out on a special stand with strain gauge head in the volume setting $(P x, P y, P z)$, developed in the laboratory of the department of mining machines and equipment of Kuzbass State Technical University [38-40]. 
As a result of experimental studies the existence of cyclical phase sequence of destruction was revealed, regardless of fracture parameters, the height of projection exposed and geometry of tools like free cutting.

Fig. 3 shows these phases of destruction depending on the different penetration depth $(h)$ of a disk tool. In contrast to free-cutting, in projection mode of destruction we observed two large fragments of rocks in the same cycle. Consequently, the cyclical nature of destruction process in projection mode [41] is characterized by two fragments and common fragmentation, and all these cycles are repeated throughout the process of destruction with the same parameters of fracture.

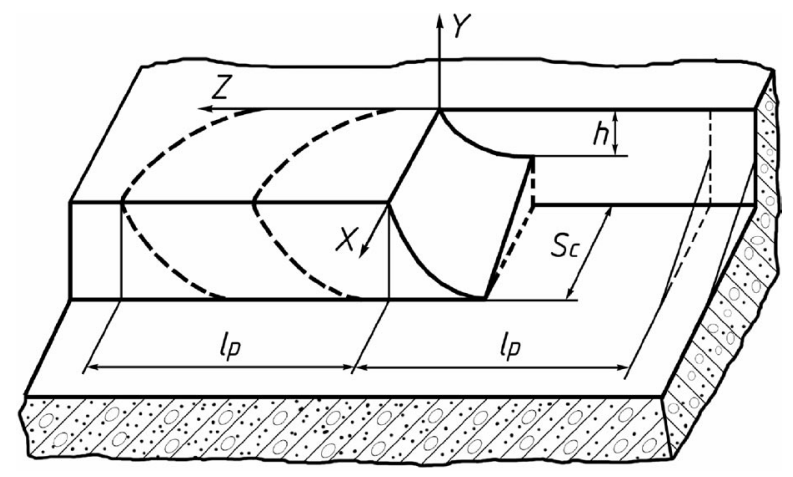

Fig. 3. Forms of fragments and the cycles of destruction with projection cutting mode

On the basis of conducted experiments it was established that phases of cycles don't depend on penetration depth $(h)$ and have the same form of fragments. Also it was revealed that when changing diameter of the tool $D$, length of a phase of destruction of $l_{p}$ remained constant.

As a result of calculations the following functional dependences of volume of the destroyed large elements of material $(V)$ on a cutting step $S_{c}$ and height of exposure of free surface $(L)$ were calculated:

- for ellipsoid:

$$
V_{e l}\left(S_{c}, L\right)=\left\{\begin{array}{l}
\frac{\pi}{6} S_{c} L\left(14.65-\frac{63.47}{S_{c}+4.33}\right), \text { where } 0.03 \leq S_{c} \leq 0.09 \mathrm{~m} \\
S_{c} \leq L \leq L_{\max }=\frac{1}{2} S_{c}^{2}+\frac{1}{2} S_{c}+3, \\
\frac{\pi}{6} S_{c} L\left(0.1 S_{c}^{2}-0.19 S_{c}+5.72\right), \text { where } 0.03 \leq S_{c} \leq 0.09 \mathrm{~m} \\
S_{c} \leq L \leq L_{\max }=-36+\frac{1080}{21+S_{c}}
\end{array}\right.
$$

- for pyramid:

$$
V_{p y r}\left(S_{c}, L\right)=\frac{V_{e l}\left(S_{c}, L\right)}{\pi}
$$

\section{Results and discussion}

Based on the functional relationship described above the chart (Fig. 4) has been plotted to show clearly the amount of damaged material, depending on the cutting step $S_{c}$, and the height of exposed surface $(L)$. In Fig. 4 solid line denotes the amount of damaged material, 
calculated on the ellipsoid, and bar line - for the pyramid. The volume of real materials shown as shaded area. The dashed line represents the average volume of destroyed material. It can be seen that the most exposed surface $L_{\max }$ (for each step of cutting) destroyed by the maximum volume is observed for $D=0.04 \mathrm{~m}, 0.05 \mathrm{~m}$ and $0.06 \mathrm{~m}$ height to the exposed surface of $L=0.07 \mathrm{~m} ; 0.055 \mathrm{~m}$ and $0.04 \mathrm{~m}$, respectively. The greatest value of volume is observed at $S_{c}=0.05 \mathrm{~m}$ and $L_{\max }=0.055 \mathrm{~m}$, confirming previously given ratio $S_{c} / L_{\max }=$ 0.91 for $V_{\max }$.

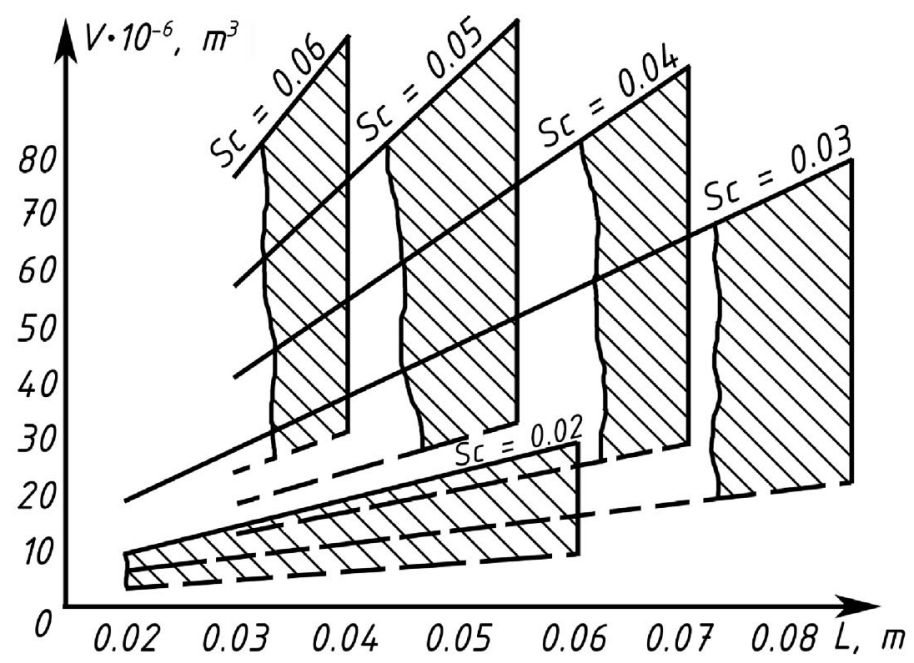

Fig. 4. Dependence of the volume of destroyed element $(V)$ in one phase of cutting cycle on the height of exposure $(L)$

We modeled real zone of destruction for outgrowth system of development with working body for the ratio $S_{c} / L_{\max }=0.91$ (Fig. 5A), from which it follows that this ratio is characterized by significant area of intact material (indicated by the dashed lines), for further destruction of which the undue increase of energy consumption is required.

Therefore, to achieve the smallest area of intact material while maintaining the maximum possible amount of damaged material we modeled simulated modes and selected the parameters of destruction $S_{c} \geq 0.035 \mathrm{~m}$ and $L=0.045 \mathrm{~m}$ (Fig. 5B).

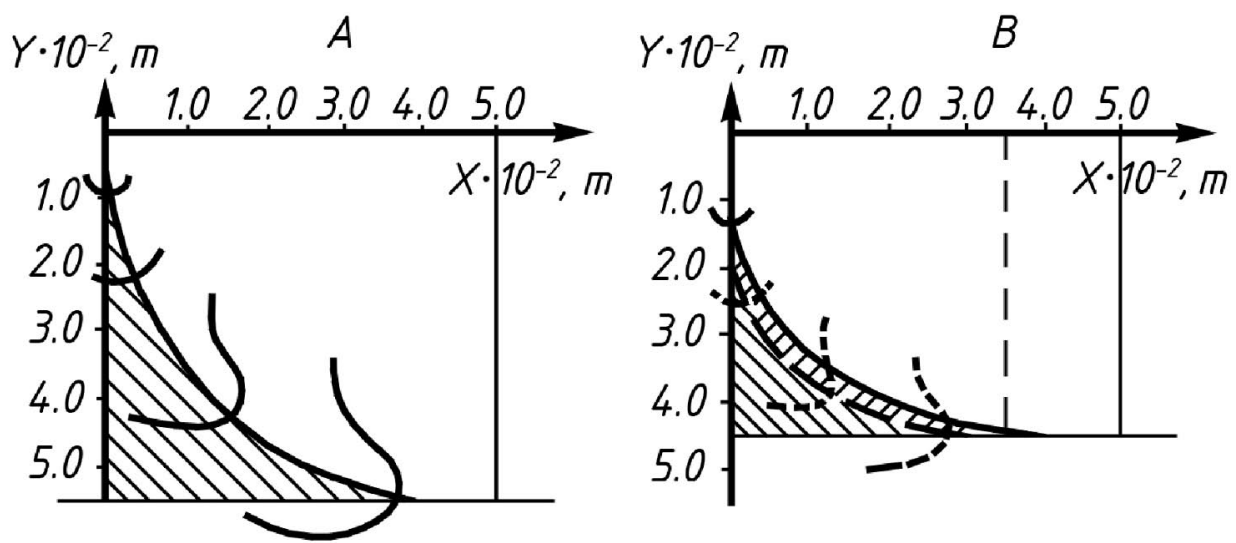

Fig. 5. The description of outgrowth disintegration in plane: A - with $S_{c}=0.05 \mathrm{~m}, L_{\max }=0.055 \mathrm{~m}$; B - with $S_{c} \geq 0.035 \mathrm{~m}, L_{\max }=0,045 \mathrm{~m}$. 
The results of theoretical and experimental studies of the volume of destruction of large elements $(V)$ depending on depth of introduction $(h)$ are given in fig. 6.

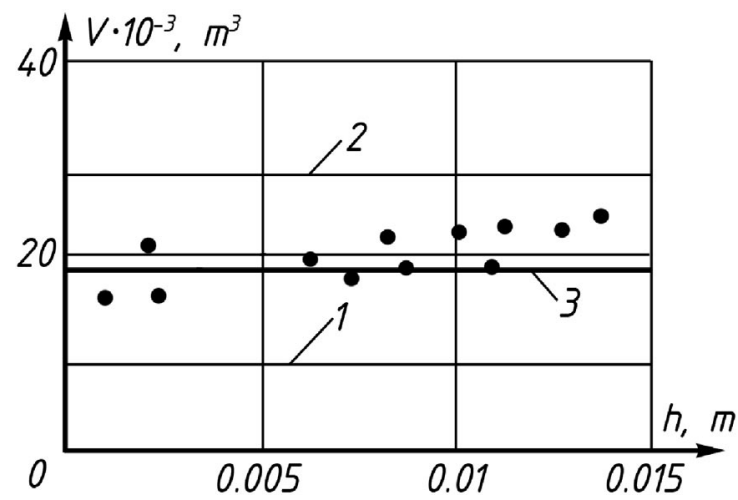

Fig. 6. The results of theoretical and experimental studies of the volume of large elements destruction $(V)$ depending on depth of introduction $h$.

Horizontal lines in Fig. 6 designate theoretical dependences of volume of destroyed material $(V)$ without deepening the disk tool. They are independent from depth of introduction of $h$ character and are calculated for a pyramid (Fig.5 A,B, line 1), an ellipsoid ((Fig.5 A,B, line 2) and the average volume of the destroyed element ((Fig.5 A,B, line 3) $V_{a v}=\left(V_{e l}+V_{p y r}\right) / 2$. Results of experimental studies are designated by points depending on the depth of penetration of $h$.

\section{Conclusions}

Results of the maximum volumes of destroyed material $\left(V_{\max }\right)$ are located between the theoretical dependences calculated on formulas of an ellipsoid and a pyramid. Therefore, the offered theoretical dependences of creation of volumes of destroyed large elements $(V)$ on influence of the disk tool without deepening are correct for depth of introduction of $h<0.015 \mathrm{~m}$. At the destruction of solid rocks the disk tool penetrates into a depth $h$ of 0.01 $\mathrm{m}$. So, defined functional dependencies are valid for the destruction of solid rocks with outgrowth mode by disk tools.

\section{References}

1. M. Tyulenev, S. Zhironkin, O. Litvin, Pollution Research, 34, 825 (2015)

2. G.E. Andreev, Min Sci and Tech 12, 445 (1991)

3. Peide Sun, Min Sci and Tech 10, 433 (1991)

4. Shixiong Zhang and Guangxu Tong, Min Sci and Tech 10, 157 (1991)

5. Yuejin Li, Singh RN, Min Sci and Tech 12, 279 (1991)

6. Lindholm US, Yeakley LM, Nagy A, Int J Rock Mech Min Sci 11181 (1974)

7. Atkinson T, Cassapi VB, Singh RN, Int J Min Geol Eng 4, 151 (1986)

8. Kulatilake PHSW, Shou G, Huang TH, Morgan RM, Int J Rock Mech Min Sci Geomech Abstr 32, 673 (1995)

9. Li HB, Zhao J, Li JR, Liu YQ, Zhou QC, Int J Rock Mech Min Sci 41, 365 (2004)

10. Goktan RM, Gunes NA, Int J Rock Mech Min Sci 42, 466 (2005) 
11. C. Dogruoz, Effect of pick blunting on cutting performance for weak-moderate rocks, Ph.D. Thesis, Mining Engineering Department, Middle East Technical University, Turkey, 144 (2010)

12. RP Janeiro, HH Einstein, Int J Fract 164, 83 (2010)

13. Zhi Cheng Tang et al., Rock Mech Rock Eng 49, 1191 (2016)

14. Ö. Erdem, T. Güyagüler, N. Demirel, The Journal of The Southern African Institute of Mining and Metallurgy, 112, 405 (2012)

15. Grasselli G, Wirth J, Egger P, Int J Rock Mech Min Sci 39, 789 (2002)

16. Balci C, Bilgin N, Comparison of small and full scale rock cutting tests to select mechanized excavation machines (Istanbul Technical University, Mining Engineering Department 2005)

17. Tatone BS, Grasselli G, Rock Mech Rock Eng 46, 657 (2013)

18. Tyulenev MA, Lesin Yu, Vik S and Zhironkin S, Proceedings of the 8th RussianChinese Symposium "Coal in the 21st Century", 333 (2016)

19. Li SC, Cheng YM, Theoret Appl Fract Mech 44, 234 (2005)

20. Thiagarajan G, J Eng Mech Asce 133, 514 (2007)

21. Resende R, Lamas LN, Lemos JV, Calcada R, Rock Mech Rock Eng 43, 741 (2010)

22. Ning Y, Yang J, An XM, Ma GW, Comput Geotech 38, 40 (2011)

23. Engin IC, Bayram F, Yasitli NE, Rock Mech Rock Eng 16, 755 (2013)

24. Dogruoz C, Bolukbasi N, Rostami J, Acar C, Rock Mech Rock Eng 49, 213 (2016)

25. Brady BHG, Brown ET, Chapama, Rock mechanics for underground mining, 2nd edn. (London, UK 1993)

26. Yagiz S, Assessment of brittleness using rock strength and density with punch penetration test, tunnelling and underground space technology (Elsevier, Amsterdam, 2009)

27. Copur H, Balci C, Tumac D, Bilgin N, Int J Rock Mech Min Sci 48, 269 (2011)

28. Khoreshok A A, Zhironkin S A and Tyulenev M A et al., IOP Conference Series: Materials Science and Engineering 142, 012122 (2016)

29. Kovalev V, Gerike B, Khoreshok A, Gerike P, Taishan Academic Forum - Project on Mine Disaster Prevention and Control, 184 (2014)

30. Aksenov VV, Khoreshok AA, Beglyakov VYu, App Mech and Mat 379, 20 (2013)

31. Lekontsev Yu, Sazhin P, Temiryaeva O, Khoreshok AA., J of Min Sci 49, 757 (2013)

32. Khoreshok AA., Ugol' 7, 67 (2002)

33. Ryzhkov YA, Gogolin VA, and Karpenko NV, Journal of Mining Science 28, 6 (1992)

34. Ryzhkov YA, Lesin YV, Gogolin VA, Karpenko NV, J of Min Sci., 32, 188 (1996)

35. Tyulenev M A, Khoreshok A A, Garina E A, Danilov S and Zhironkin S, Proceedings of the 8th Russian-Chinese Symposium "Coal in the 21st Century: Mining, Processing, Safety", 111 (2016)

36. Zhironkin SA, Khoreshok AA, Tyulenev MA et al., IOP Conference Series: Materials Science and Engineering 142012127 (2016)

37. Zhironkin SA, Khoreshok AA, Tyulenev MA, Barysheva GA, Hellmer MC, IOP Conference Series: Materials Science and Engineering 142, 012127 (2016)

38. Tyulenev MA, Zhironkin SA, Garina EA, International Journal of Mining and Mineral Engineering 7, 363 (2016) 
39. Tyulenev MA, Gvozdkova TN, Zhironkin SA, Garina EA, Geotechnical and Geological Engineering, 35, 203 (2017)

40. Tyulenev M, Zhironkin S, Kolotov K and Garina E, Pollution Research, 35, 221 (2016)

41. Gölbasi, O.; Demirel, N. Proceedings of the International Mining Congress and Exhibition of Turkey (Antalya, Turkey, 14-17 April 2015) 